\title{
Insecticide susceptibility status and knockdown resistance $(k d r)$ mutation in Aedes albopictus in China
}

Yong Wei ${ }^{1,2^{*}}$, Xueli Zheng ${ }^{2 *}$, Song He ${ }^{1 *}$, Xuli Xin ${ }^{1}$, Jiachun Zhang ${ }^{1}, \mathrm{Ke} \mathrm{Hu}^{2}$, Guofa Zhou ${ }^{3}$ and Daibin Zhong ${ }^{3}$

\begin{abstract}
Background: Aedes (Stegomyia) albopictus (Skuse, 1894) is the main vector of dengue virus in China. The resistance to insecticides is a huge obstacle for the control of this species, and determining its resistance status and mechanisms in China is essential for the implementation of vector management strategies.

Methods: We have investigated the larval and adult resistance status of Ae. albopictus to deltamethrin in eight field populations in China. Mutations at the voltage-gated sodium channel gene, related to the knockdown resistance $(k d r)$ effect, were detected by sequencing of PCR products. The eight field populations were examined for pyrethroid resistance using the World Health Organization standard bioassays, and the association between the mutations and phenotypic resistance was tested.

Results: The eight field populations of larvae of Ae. albopictus in China exhibited high resistance to deltamethrin; the $R_{50}$ values ranged from 12 (ZJ) to 44 (GZ). Adult bioassay revealed that Ae. albopictus populations were resistant to deltamethrin (mortality rate $<90 \%$ ), except ZJ population (probably resistant, mortality rate $=93.5 \%$ ). Long knockdown time in the field populations was consistent with low mortality rates in adult bioassay. F1534S mutation showed increased protection against deltamethrin in all populations except BJ and SJZ populations, whereas I1532T mutation showed increased protection against deltamethrin in only BJ population.

Conclusion: There were different degrees of resistance to deltamethrin in field Ae. albopictus populations in China. The longest knockdown time and lowest mortality rate observed in Ae. albopictus population in Guangzhou indicate the severity of high resistance to deltamethrin. The patchy distribution of deltamethrin resistance and $k d r$ mutations in Ae. albopictus mosquitoes suggests the necessity for resistance management and developing counter measures to mitigate the spread of resistance.
\end{abstract}

Keywords: Aedes albopictus, Deltamethrin, Resistance, kdr

\footnotetext{
*Correspondence: smuweiyong@163.com; zhengxueli2001@126.com; maxhe@163.com

${ }^{1}$ Clinical Laboratory, Shenzhen Qianhai Shekou Free Trade Zone Hospital, Shenzhen, China

${ }^{2}$ Department of Pathogen Biology, School of Public Health, Southern Medical University, Guangzhou, China

Full list of author information is available at the end of the article
}

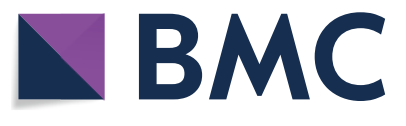

2021. Open Access This article is licensed under a Creative Commons Attribution 4.0 International License, which permits use, sharing, adaptation, distribution and reproduction in any medium or format, as long as you give appropriate credit to the original author(s) and the source, provide a link to the Creative Commons licence, and indicate if changes were made. The images or other third party material in this article are included in the article's Creative Commons licence, unless indicated otherwise in a credit line to the material. If material is not included in the article's Creative Commons licence and your intended use is not permitted by statutory regulation or exceeds the permitted use, you will need to obtain permission directly from the copyright holder. To view a copy of this licence, visit http://creativecommons.org/licenses/by/4.0/. The Creative Commons Public Domain Dedication waiver (http://creativecommons.org/publicdomain/zero/1.0/) applies to the data made available in this article, unless otherwise stated in a credit line to the data. 


\section{Graphical Abstract}

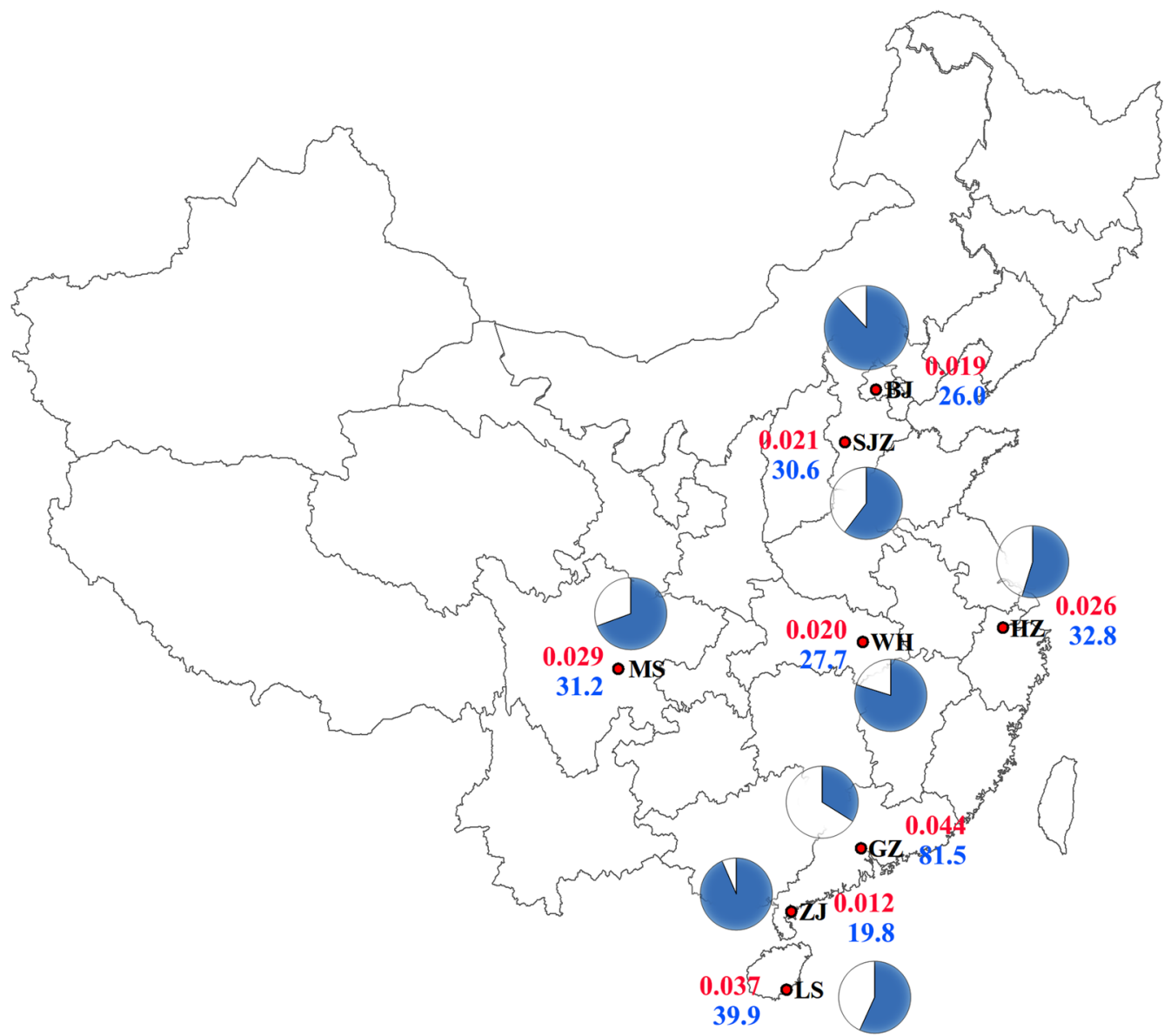

\section{Background}

Aedes (Stegomyia) albopictus (Skuse, 1894) is the main vector of dengue virus in China because of its wide range in nearly one third of China from north of $41^{\circ} \mathrm{N}$ latitude to the southern reaches compared to the distribution of Ae. aegypti, limited to Hainan, Yunnan and a small area of the southernmost part of Guangdong Province $[1,2]$. There were 69,321 cases of dengue reported and annual case numbers with striking variations in mainland China during 1990-2014 [3]. There were 5458 imported dengue cases distributed in 734 counties, 29 provinces and 59,183 indigenous dengue cases distributed in 314 counties and 13 provinces in mainland China during 2014-2018 [4]. The provinces affected by imported and indigenous dengue have expanded geographically from the southern to the northern parts of China [5], such as Henan Province in temperate central China where indigenous dengue cases occurred in 2013 [6]. Aedes albopictus is also the vector of three other important human viral diseases: yellow fever, chikungunya and Zika [7]. These diseases are a public health concern in China.

At present, due to the lack of effective drugs and vaccine for most Ae. albopictus transmitted parasites, except the vaccine for yellow fever virus, control of the parasites vectored by Ae. albopictus depends mostly on vector population control [8-10]. Reduction of larval breeding sites and use of insecticides are the major strategies for the control of vector mosquitoes [11-13]. Pyrethroids have been widely used as indoor or field sprays for mosquito control in China because of their low mammalian toxicity and rapid knockdown effect $[9,14,15]$. For example, $>27,000 \mathrm{~kg}$ of pyrethroids was used for ultralowvolume spraying to control adult mosquitoes during the outbreak of dengue in Guangzhou in 2014 [16]. The development of resistance is one of the main problems faced due to extensive and prolonged use of pyrethroids [15]. The populations of Ae albopictus are subject to a continuous selection pressure of pyrethroids, which contributes to the fast emerging insecticide resistance [16]. 
It is important to monitor the susceptibility of mosquito population and understand the resistance mechanisms for controlling the local mosquito population.

The target-site insensitivity is the main resistance mechanism of Ae. albopictus against insecticides, in addition to increased metabolic detoxification [11, 17, 18]. The target site insensitivity results from non-synonymous mutation in the voltage-gated sodium channel $(V G S C)$ gene, which has been shown to be correlated to phenotypic resistance to pyrethroids $[19,20]$. The modification of VGSC protein weakens the effect of pyrethroids on the sodium channels of the nervous system via reduction or elimination of the binding affinity of the pyrethroids to proteins [21, 22]. VGSC protein is composed of four homologous domains (I-IV), of which domain III is the major one having non-synonymous mutations associated with pyrethroid resistance in Ae. albopictus, such as F1534S, F1534L, F1534C and I1532T [16, 19, 23-26]. In the present study, we investigated phenotypic resistance of Ae. albopictus adults collected from eight field populations across China and examined mutations in the partial domain III of VGSC gene. Moreover, the association between phenotypic resistance and $k d r$ mutation was analyzed to provide complementary evidence for resistance detection of local mosquito populations at the gene level.

\section{Methods \\ Mosquito samples}

According to our previous sampling method [27], mosquito eggs were collected from breeding sites in Lingshui (LS, $110^{\circ} 01^{\prime} 59^{\prime \prime} \mathrm{E}, 18^{\circ} 30^{\prime} 27^{\prime \prime} \mathrm{N}$ ), Zhanjiang (ZJ, $\left.109^{\circ} 42^{\prime} 60^{\prime \prime} \mathrm{E}, 21^{\circ} 05^{\prime} 37^{\prime \prime} \mathrm{N}\right)$, Guangzhou (GZ, $113^{\circ} 19^{\prime} 42^{\prime \prime} \mathrm{E}$, $23^{\circ} 11^{\prime} 15^{\prime \prime} \mathrm{N}$ ), Meishan (MS, 103 $52^{\prime} 01^{\prime \prime} \mathrm{E}, 30^{\circ} 11^{\prime} 55^{\prime \prime} \mathrm{N}$ ), Wuhan (WH, $\left.114^{\circ} 22^{\prime} 39^{\prime \prime} \mathrm{E}, \quad 30^{\circ} 30^{\prime} 30^{\prime \prime} \mathrm{N}\right)$, Hangzhou (HZ, $120^{\circ} 07^{\prime} 09^{\prime \prime} \mathrm{E}, \quad 30^{\circ} 18^{\prime} 42^{\prime \prime} \mathrm{N}$ ), Shijiazhuang (SJZ, $114^{\circ} 27^{\prime} 49^{\prime \prime} \mathrm{E}, \quad 37^{\circ} 54^{\prime} 55^{\prime \prime} \mathrm{N}$ ), Beijing (BJ, $116^{\circ} 11^{\prime} 45^{\prime \prime} \mathrm{E}$, $39^{\circ} 51^{\prime} 36^{\prime \prime} \mathrm{N}$ ) in China from 20 July to 25 September 2019. The collected eggs were brought back to the laboratory and reared to adults (namely F0 generation) at $28 \pm 1{ }^{\circ} \mathrm{C}$ and $80 \pm 5 \%(\mathrm{RH})$, under a 16:8 h (light:dark) photoperiod. The species of Ae. albopictus was identified by using morphological keys as described by Lu et al. [28]. The susceptible laboratory colony of Ae. albopictus was collected from Foshan City in 1983 and then kept in the laboratory without insecticide exposure.

\section{Larval resistance bioassays}

Mosquito larval resistance bioassays were conducted using deltamethrin (94.62\% pure) from the Chinese Center for Disease Control and Prevention following WHO guidelines [29]. Twenty-five 3-4-instar Ae. albopictus larvae from F1-generation field populations were added to $99 \mathrm{ml}$ of dechlorinated tap water and $1 \mathrm{ml}$ of different concentrations of deltamethrin solution. Six concentration gradients, providing a range of mortalities between 10 and $90 \%$, were tested during the experiment, three replicates per concentration. Larval mortality was recorded after $24 \mathrm{~h}$ exposure, and the $\mathrm{LD}_{50}$ values (the $50 \%$ mortality lethal concentration) were calculated.

\section{Adult resistance bioassays}

Non-blood-fed female mosquitoes aged 3-5 days from F1 field populations and the susceptible laboratory colony were used for the resistance test against $0.03 \%$ deltamethrin following the standard WHO tube test protocol [30]. Adult bioassays were conducted with 20-28 mosquitoes per replicate and 10-20 replicates per population. The number of adult mosquitoes knocked down was recoded every $10 \mathrm{~min}$ during the 60 -min exposure period and used to calculate the values of $50 \%$ knockdown times $\left(\mathrm{KDT}_{50}\right)$ and $95 \%$ knockdown times $\left(\mathrm{KDT}_{95}\right)$. Mortality was calculated after the mosquitoes were transferred to holding tubes and maintained on a $10 \%$ sucrose solution for $24 \mathrm{~h}$ of recovery. The dead and survived mosquitoes were collected and stored individually in 95\% alcohol for subsequent DNA analysis.

\section{DNA isolation and PCR amplification}

The genomic DNA of the mosquitoes was individually extracted using the Insect DNA Kit (Omega Bio-tek, Norcross, GA, USA), following the manufacturer's protocol. The quality and concentration of the extracted DNA were evaluated with a NanoDrop ${ }^{\mathrm{TM}} 2000$ c spectro- $^{-}$ photometer (Thermo Scientific, Wilmington, DE, USA). Extracted DNA was stored at $-20{ }^{\circ} \mathrm{C}$ or used immediately for PCR. Partial domain III of VGSC gene (containing F1534 and I1532) was amplified using forward primer aegSCF7 (5'-GAG AAC TCG CCG ATG AAC TT-3') and reverse primer aegSCR8 (5'-TAG CTT TCA GCG GCT TCT TC-3') [19]. The PCR reaction mixture consisted of $100 \mathrm{ng}$ genomic DNA, $15 \mu \mathrm{l} 2 \times$ PCR Master Mix (Promega, Madison, WI, USA), $1 \mu \mathrm{l}(10 \mu \mathrm{M})$ forward and reverse primers, and $\mathrm{dd}_{2} \mathrm{O}$, in a final volume of $30 \mu \mathrm{l}$. The PCR cycling conditions were as follows: $95{ }^{\circ} \mathrm{C}$ for $5 \mathrm{~min}$, followed by 35 cycles of $95^{\circ} \mathrm{C}$ for $30 \mathrm{~s}$, $60{ }^{\circ} \mathrm{C}$ for $30 \mathrm{~s}$ and $72{ }^{\circ} \mathrm{C}$ for $40 \mathrm{~s}$, with a final extension at $72{ }^{\circ} \mathrm{C}$ for $10 \mathrm{~min}$. The quality of PCR products was ascertained by $1.5 \%$ agarose gel electrophoresis following ethidium bromide stain. The PCR product was purified using a gel extraction kit (Omega Bio-tek) and sequenced directly with aegSCR8 using the ABI 3730XL automatic sequencer (Applied Biosystems, Guangzhou, China). 


\section{Data analysis}

The authenticity of the sequences was corroborated through the BLAST program (https://blast.ncbi.nlm. nih.gov/Blast.cgi), considering an identity percentage $>95 \%$. The sequences were aligned and analyzed by using BioEdit v.7.2.5 software [31]. $\mathrm{LD}_{50}, \mathrm{KDT}_{50}$ and $\mathrm{KDT}_{95}$ were estimated using the log-probit models, and mortality rates were calculated in each population. A Chi-square test was used to compare differences of mortalities in adult resistance bioassays among different field populations. $\mathrm{RR}_{50} / \mathrm{KRR}_{50} / \mathrm{KRR}_{95}$ was calculated as $\mathrm{LD}_{50} / \mathrm{KDT}_{50} / \mathrm{KDT}_{95}$ of field population divided by $\mathrm{LD}_{50} /$ $\mathrm{KDT}_{50} / \mathrm{KDT}_{95}$ of laboratory strain, respectively. Resistance status was classified according to WHO (2016) criteria [30]: for adult bioassays, resistant if mortality $<90 \%$, probably resistant if mortality between 90 and $98 \%$ and susceptible if mortality $>98 \%$; for larval bioassays, susceptible if $\mathrm{RR}_{50}<5$, moderately resistant if $5<\mathrm{RR}_{50}<10$ and highly resistant if $R_{50}>10$. The association between nonsynonymous mutation and the resistance phenotype was verified by Fisher's exact test or Chi-square test, and the odds ratio (OR) was calculated for each mutation.

\section{Results}

\section{Larval resistance bioassays}

The eight field populations of larval Ae. albopictus in China exhibited high resistance to deltamethrin (Table 1). The observed $\mathrm{LC}_{50}$ values of field populations were 0.012 (ZJ) to 0.044 (GZ) mg/l; correspondingly, the $\mathrm{RR}_{50}$ values ranged from $12(\mathrm{ZJ})$ to $44(\mathrm{GZ})$.

\section{Adult resistance bioassays}

The eight field populations of adult Ae. albopictus in China exhibited resistance to deltamethrin (Fig. 1, Table 2). The highest mortality rate was observed for ZJ population (mortality rate $=93.5 \%, 95 \% \mathrm{CI}=90.8$ - 96.2\%), which was probable resistance. The other

Table 1 Resistance to deltamethrin in larval Ae. albopictus from eight different populations in China

\begin{tabular}{lcc}
\hline Populations & $\mathrm{LC}_{50}(95 \% \mathrm{Cl})(\mathrm{mg} / \mathrm{l})$ & $\mathrm{RR}_{50}{ }^{\mathrm{a}}$ \\
\hline Lab & $0.001(0.001,0.001)$ & 1.00 \\
$\mathrm{BJ}$ & $0.019(0.009,0.025)$ & 19.0 \\
$\mathrm{SJZ}$ & $0.021(0.011,0.027)$ & 21.0 \\
$\mathrm{HZ}$ & $0.026(0.014,0.033)$ & 26.0 \\
WH & $0.020(0.007,0.027)$ & 20.0 \\
MS & $0.029(0.018,0.035)$ & 29.0 \\
$\mathrm{GZ}$ & $0.044(0.036,0.049)$ & 44.0 \\
ZJ & $0.012(0.005,0.015)$ & 12.0 \\
LS & $0.037(0.027,0.042)$ & 37.0 \\
\hline
\end{tabular}

\footnotetext{
${ }^{a} R_{50}$ : resistance ratio, $\mathrm{LC} 50$ test population/LC50 laboratory-susceptible strain
}

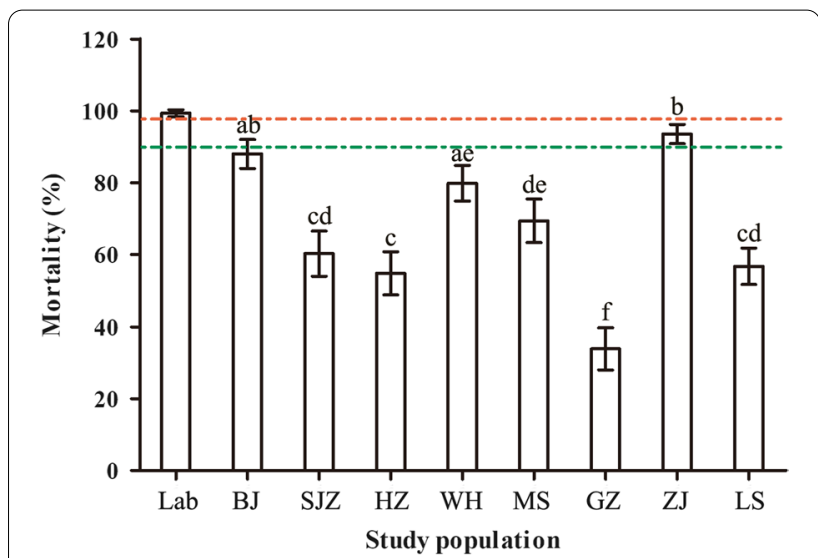

Fig. 1 Mortalities observed with deltamethrin for the adult $A$ e. albopictus of the eight field populations and the susceptible laboratory colony. The green and red broken lines indicate respectively the mortality at 90\% and 98\%. Error bars indicate 95\% confidential interval (CI). Different letters above bars represent significant differences between the field populations at the adjusted $P$-value $<0.00179$

mortality rates of field populations were $<90 \%$, with the least mortality rate of $33.9 \%$ in $\mathrm{GZ}$ population. A statistically significant difference was observed among mortality rates of the eight populations $\left(\chi^{2}=338.15\right.$, $\mathrm{df}=7, P<0.001)$. Most pairwise differences of 28 pairs between the field populations were significant (adjusted $P$-value $<0.00179)$, except no significant differences between SJZ and each one of HZ, MS and LS; between LS and $\mathrm{HZ} / \mathrm{MS}$; between BJ and $\mathrm{WH} / \mathrm{ZJ}$; between $\mathrm{WH}$ and MS.

The knockdown time for deltamethrin showed a linear probit for knockdown rates with time in the field populations (Fig. 2, Table 2). The observed $\mathrm{KDT}_{50}$ values were $19.8(\mathrm{ZJ})$ to $81.5(\mathrm{GZ}) \mathrm{min}$, and the observed $\mathrm{KDT}_{95}$ values were $56.2(\mathrm{ZJ})$ to 306.7 (GZ) min for deltamethrin. The $50 \%$ knockdown time $\left(\mathrm{KDT}_{50}\right)$ was 4.3 times (maximum times) in GZ population compared to the susceptible laboratory colony and nearly 1.0 times (minimum times) for ZJ population. There was a similar increase in the $95 \%$ knockdown time $\left(\mathrm{KDT}_{95}\right)$ in field populations compared to the susceptible laboratory colony. Long knockdown time in the field populations was consistent with low mortality rates in adult bioassay.

\section{Detection of kdr mutations in Ae. albopictus}

DNA was individually isolated from 18 to 24 dead and 20-24 alive deltamethrin-exposed adult Ae. albopictus mosquitoes in each field population. PCR amplification and sequencing of the partial domain III of the VGSC gene resulted in a 195-bp fragment for each study subject, with no insertions or deletions. Eight codon mutations 
Table 2 Knockdown time and mortality rate of Ae. albopictus populations in China using the standard WHO tube resistance bioassay against $0.03 \%$ deltamethrin

\begin{tabular}{lllllll}
\hline Population & $\mathrm{n}$ & $\mathrm{KDT}_{50}(95 \% \mathrm{Cl})$ & $\mathrm{KRR}_{50}$ & $\mathrm{KDT}_{95}(95 \% \mathrm{Cl})$ & $\mathrm{KRR}_{95}$ & 24-h mortality (95\% Cl) \\
\hline Lab & 388 & $18.9(16.8-20.8)$ & 1.0 & $47.6(41.7-56.7)$ & 1.0 & $99.3 \%(98.4-100 \%)$ \\
BJ & 348 & $26.0(23.1-28.7)$ & 1.4 & $63.8(54.8-79.0)$ & 1.3 & $88.0 \%(84.0-92.0 \%)$ \\
SJZ & 327 & $30.6(29.3-31.9)$ & 1.6 & $74.0(68.4-81.3)$ & 1.6 & $60.3 \%(54.0-66.5 \%)$ \\
HZ & 362 & $32.8(30.1-35.7)$ & 1.7 & $84.8(72.4-105.6)$ & 1.8 & $54.8 \%(48.7-60.8 \%)$ \\
WH & 343 & $27.7(26.4-29.0)$ & 1.5 & $76.2(69.9-84.4)$ & 1.6 & $79.8 \%(74.9-84.8 \%)$ \\
MS & 305 & $31.2(29.7-32.7)$ & 1.7 & $87.4(79.1-98.6)$ & 1.8 & $69.4 \%(63.3-75.4 \%)$ \\
GZ & 346 & $81.5(72.4-96.0)$ & 4.3 & $306.7(225.5-474.9)$ & 6.4 & $33.9 \%(28.0-39.7 \%)$ \\
ZJ & 424 & $19.8(17.3-22.2)$ & 1.0 & $56.2(48.0-69.8)$ & 1.2 & $93.5 \%(90.8-96.2 \%)$ \\
LS & 460 & $39.9(35.1-46.2)$ & 2.1 & $117.7(88.0-198.5)$ & 2.5 & $56.8 \%(51.7-61.9 \%)$ \\
\hline
\end{tabular}

$\mathrm{KDT}_{50}$ : time in minutes when $50 \%$ of the tested mosquitoes were knocked down; $95 \% \mathrm{Cl}$ refers to $95 \%$ confidence interval

$\mathrm{KRR}_{50}$ : knockdown resistant ratio was calculated as $\mathrm{KDT}_{50}$ of field population divided by $\mathrm{KDT}_{50}$ of laboratory strain;

$\mathrm{KDT}_{95}$ : time in minutes when $95 \%$ of the tested mosquitoes were knocked down;

$\mathrm{KRR}_{95}: \mathrm{KRR}_{95}$ was calculated as the ratio of $\mathrm{KDT}_{95}$ of field population to $\mathrm{KDT}_{95}$ of laboratory strain

Lab, the susceptible laboratory colony; BJ, Beijing; SJZ, Shijiazhuang; HZ, Hangzhou; WH, Wuhan; MS, Meishan; GZ, Guangzhou; ZJ, Zhanjiang; LS, Lingshui

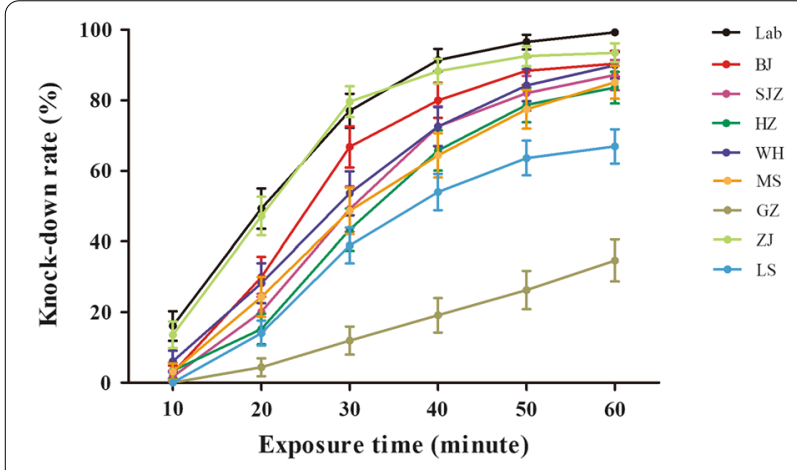

Fig. 2 Evolution of the knockdown rates for the adult Ae. albopictus of the eight field populations and the susceptible laboratory colony due to exposure to deltamethrin
To determine the impact of $k d r$ mutations at codons 1532 and 1534 on pyrethroid resistance, four kinds of mutations (I1532T, F1534S, F1534C and F1534L) were analyzed separately for their associations with deltamethrin resistance (Table 3). In all the populations, we found that F1534S and I1532T mutation frequency was significantly higher in the resistant compared to the susceptible mosquitoes; moreover, F1534S and I1532T conferred protection against deltamethrin, with odds ratios of 2.509 for F1534S $(P<0.001)$ and 1.864 for I1532T $(P<0.05)$. F1534S mutation showed increased protection against deltamethrin in all populations except BJ and SJZ populations, whereas I1532T mutation showed increased protection against deltamethrin in only BJ population (odds ratio $=4.200, P=0.019$ ).

\section{Discussion}

The emergence and spread of insecticide resistance are the biggest challenges to controlling vector-borne disease transmission [32]. Because many cities in China are threatened by the risk of imported dengue and local cases every year, various insecticides will inevitably be used occasionally to kill mosquitoes [33, 34]. Particularly in Guangzhou, the largest city in southern China and the epicenter of dengue outbreaks in China, the Ae. albopictus population has rapidly developed high resistance to deltamethrin $[16,23]$. In the present study, our results showed there were different degrees of resistance to deltamethrin in field Ae. albopictus populations in China. Longer knockdown time and lower mortality rate were observed in the Guangzhou population of Ae. albopictus against deltamethrin, while shorter knockdown time and higher mortality rate in Zhanjiang population. In

\section{Association between kdr mutations at codons and pyrethroid resistance}

Among 334 $k d r$ genotyping samples, 166 individuals were classified as "resistant" (being alive after the $24 \mathrm{~h}$ recovery period in the WHO tube bioassay) and 168 were "susceptible" (being dead after the $24 \mathrm{~h}$ recovery period). 


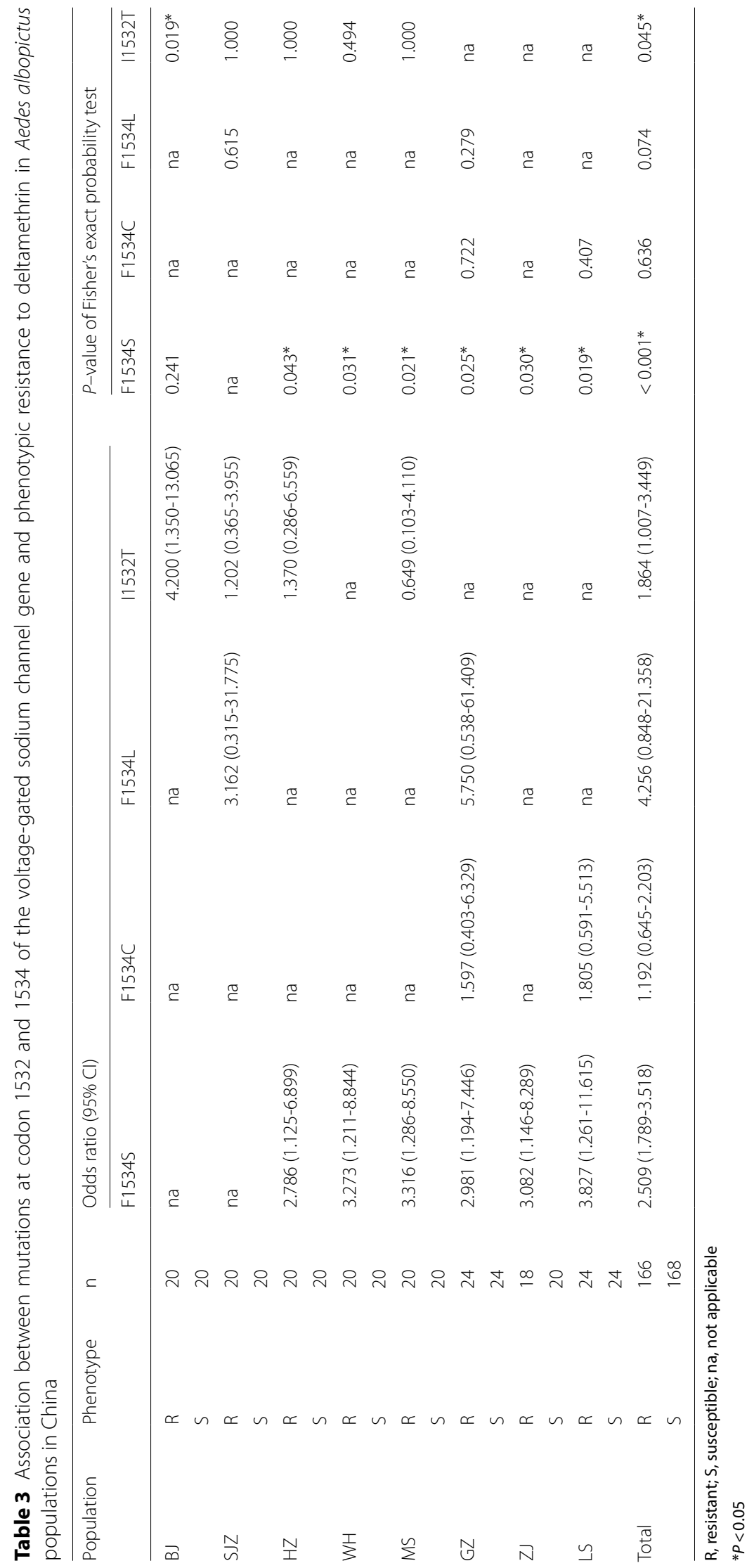


addition to the Zhanjiang population of Ae. albopictus showing probable resistance, other populations showed obvious resistance with different levels to deltamethrin. This might be related to the sampling sites in Zhanjiang from rural areas where the amount and frequency of insecticide use are relatively small compared with that in urban areas $[25,35,36]$.

Rapidly emerging and widely distributed insecticide resistance is bound to affect mosquito control management and threaten the prevention and control of dengue, so it is important to develop suitable and updated guidelines for insecticide usage. It has been reported that $\mathrm{Ae}$. albopictus larvae and adults are resistant to pyrethroid insecticides in many parts of China [37-41]. Thus, the sensitivity to current insecticides should be restored by using other highly effective and sensitive insecticides to delay the spread of resistance. For example, Su et al. suggested using malathion against adult mosquitoes and hexaflumuron or Bti against larvae for dengue vector control in Guangzhou [16]. Most cities' mosquitoes in Zhejiang Province were susceptible to alpha-cypermethrin, lambda-cyhalothrin and fenitrothion, which could be used in turn to control vectors in place of highly resistant insecticides [39]. Adding piperonyl butoxide to insecticides may also be an effective formulation for resistance management [38]. High resistance to deltamethrin could lead to cross resistance to other insecticides, such as pyriproxyfen [16]. WHO recommends that rotations, mosaics and mixtures of insecticides among which there is no cross-resistance be applied in field mosquito control and insecticide resistance management [42]. Appropriate insecticides should be selected based on information obtained from insecticide resistance surveillance and used strictly following scientific guidance [42, 43].

Using the mosquito samples across China, we established that $k d r$ mutation conferred protection against deltamethrin in Ae. albopictus by an odds ratio of 2.509 for F1534S and 1.864 for I1532T. The $k d r$ mutation in the VGSC genes is one indicator of mosquito resistance to pyrethroid insecticides. I1532T and F1534S/C/L mutations have been previously reported in Ae. albopictus from Italy, Greece, Brazil and different areas of China [23, $24,26,40,44]$. The cross-continent distribution of conserved I1532T and F1534S/C/L mutations may reflect the importance of this amino acid residue in adapting to pyrethroid selection pressure. In this study, I1532T mutation was observed in BJ, SJZ, HZ, WH and MS populations, but it conferred protection against deltamethrin only in BJ population. F1534S was observed in all populations except SJZ population, and it conferred protection against deltamethrin in all populations except BJ and SJZ populations. The period in which the climate is suitable for mosquito survival is longer in southern subtropical areas than in northern areas (BJ and SJZ populations). The relatively low temperatures and dry climate in the north may not be suitable for mosquito survival, reproduction and dispersal, resulting in lower allele richness and population diversity in northern populations [45, 46]. Moreover, the frequency and duration of insecticide use in northern areas are less than those in the south [41]. In our previous study [27], it has been suggested that Ae. albopictus populations from southern-western China may have an evolutionary advantage over those from eastern-central-northern China. Therefore, F1534S may confer protection against deltamethrin in BJ and SJZ populations of Ae. albopictus in the future. F1534C was observed in GZ and LS populations, and F1534L was observed in SJZ and GZ populations, but they were not significantly associated with resistance to deltamethrin in these populations. These mutations conferring no protection against deltamethrin might be restricted by regions or affected by the number of samples tested in each region. All in all, these mutations in VGSC genes have affected or are affecting local mosquito resistance to deltamethrin in the studied populations.

We recognize several limitations in our study. First, a survey on the resistance to more insecticides would be ideal. Second, mutations of domains I, II and IV of $V G S C$ gene, which were not sequenced in the present study, might affect resistance to deltamethrin, though these mutations have been reported in few studies in Ae. albopictus populations in China. Third, detecting the mutations of acetylcholinesterase, $\gamma$-aminobutyric and metabolic detoxification enzymes would contribute to understand comprehensively the cause of the high level of resistance to deltamethrin in Ae. albopictus populations in China $[47,48]$.

The findings of this study have important implication on the control of Ae. albopictus. First, it is required to monitor the insecticide resistance status and develop efficient mosquito control strategies for the patchy distribution of deltamethrin resistance in Ae. albopictus populations. Second, the $k d r$ mutation may be a useful biomarker for pyrethroid resistance surveillance in some Ae. albopictus populations with a significant association between $k d r$ mutation and protection from deltamethrin in China. Moreover, further work is required to solve the limitations we mentioned in this study for gaining a full understanding of the status of pyrethroid resistance and underlying mechanisms in field Ae. albopictus populations in China.

\section{Conclusions}

This study reported not only the resistance status to deltamethrin in field Ae. albopictus populations in China, but also the association between $k d r$ mutation 
and protection from deltamethrin. The significant association raised the possibility that $k d r$ mutation may be a viable biomarker for deltamethrin resistance surveillance in $A e$. albopictus. The patchy distribution of deltamethrin resistance and $k d r$ mutations in Ae. albopictus mosquitoes suggests the necessity for resistance management and developing countermeasures to mitigate the spread of resistance.

\section{Abbreviations}

kdr: Knockdown resistance; VGSC: Voltage-gated sodium channel; WHO: World Health Organization.

\section{Acknowledgements}

We sincerely thank Jiatian Wang, Yuanhuan Wei, Zihao Zheng, Yulan Chen, Hao Zhang, Guangsheng Qiu and Weihao Zou for their assistance in collecting mosquito samples from different provinces.

\section{Authors' contributions}

YW, XZ, SH and DZ conceived and designed the experiments. YW, SH, XX, JZ and $\mathrm{KH}$ performed the experiments. YW and DZ analyzed the data. YW, XZ, DZ and $G Z$ wrote and revised the manuscript. All authors read and approved the final manuscript.

\section{Funding}

This work was supported by the National Natural Science Foundation of China (no. 31630011) and the Science and Technology Planning Project of Guangzhou (no. 201804020084).

\section{Availability of data and materials}

The data sets supporting the results are included within the article. Nucleotide sequence data reported in this paper have been deposited to the NCBI GenBank database under accession numbers OK300097-OK300430.

\section{Declarations}

\section{Ethics approval and consent to participate}

No specific permits were required for the field studies. After explanation of the purposes and activities of the study, oral consent was obtained from the local participating residents prior to mosquito collection. No sites were protected by law and this study did not involve endangered or protected species.

\section{Consent for publication}

Not applicable.

\section{Competing interests}

The authors declare that they have no competing interests.

\section{Author details}

${ }^{1}$ Clinical Laboratory, Shenzhen Qianhai Shekou Free Trade Zone Hospital, Shenzhen, China. ' Department of Pathogen Biology, School of Public Health, Southern Medical University, Guangzhou, China. ${ }^{3}$ Program in Public Health, College of Health Sciences, University of California, Irvine, CA, USA.

Received: 7 August 2021 Accepted: 10 November 2021

Published online: 18 December 2021

\section{References}

1. Wu F, Liu Q, Lu L, Wang J, Song X, Ren D. Distribution of Aedes albopic tus (Diptera: Culicidae) in northwestern China. Vector Borne Zoonotic Dis. 2011:11:1181-6.

2. Guo YH, Lai SJ, Liu XB, Li GC, Yu HJ, Liu QY. Governmental supervision and rapid detection on dengue vectors: An important role for dengue control in China. Acta Trop. 2016;156:17-21.
3. Lai S, Huang Z, Zhou H, Anders KL, Perkins TA, Yin W, et al. The changing epidemiology of dengue in China, 1990-2014: a descriptive analysis of 25 years of nationwide surveillance data. BMC Med. 2015;13:100.

4. Yue Y, Liu X, Xu M, Ren D, Liu Q. Epidemiological dynamics of dengue fever in mainland China, 2014-2018. Int J Infect Dis. 2019;86:82-93.

5. Lin H, Wang X, Li Z, Li K, Lin C, Yang H, et al. Epidemiological characteristics of dengue in mainland China from 1990 to 2019: A descriptive analysis. Medicine. 2020;99:e21982.

6. Huang $X Y, M a H X$, Wang HF, Du YH, Su J, Li XL, et al. Outbreak of dengue Fever in central China, 2013. Biomed Environ Sci. 2014;27:894-7.

7. Gratz NG. Critical review of the vector status of Aedes albopictus. Med Vet Entomol. 2004;18:215-27.

8. Abramides GC, Roiz D, Guitart R, Quintana S, Guerrero I, Giménez N. Effectiveness of a multiple intervention strategy for the control of the tiger mosquito (Aedes albopictus) in Spain. Trans R Soc Trop Med Hyg. 2011;105:281-8.

9. Banks SD, Murray N, Wilder-Smith A, Logan JG. Insecticide-treated clothes for the control of vector-borne diseases: a review on effectiveness and safety. Med Vet Entomol. 2014;28(Suppl 1):14-25.

10. Fonseca DM, Unlu I, Crepeau T, Farajollahi A, Healy SP, Bartlett-Healy K, et al. Area-wide management of Aedes albopictus Part 2: gauging the efficacy of traditional integrated pest control measures against urban container mosquitoes. Pest Manag Sci. 2013;69:1351-61.

11. Moyes CL, Vontas J, Martins AJ, Ng LC, Koou SY, Dusfour I, et al. Contemporary status of insecticide resistance in the major Aedes vectors of arboviruses infecting humans. PLoS Negl Trop Dis. 2017;1 :e0005625.

12. Roiz D, Wilson AL, Scott TW, Fonseca DM, Jourdain F, Müller P, et al. Integrated Aedes management for the control of Aedes-borne diseases. PLoS Negl Trop Dis. 2018;12:e0006845.

13. Marcombe S, Chonephetsarath S, Thammavong P, Brey PT. Alternative insecticides for larval control of the dengue vector Aedes aegypti in Lao PDR: insecticide resistance and semi-field trial study. Parasit Vectors. 2018;11:616.

14. Caputo B, lenco A, Manica M, Petrarca V, Rosà R, della Torre A. New adhesive traps to monitor urban mosquitoes with a case study to assess the efficacy of insecticide control strategies in temperate areas. Parasit Vectors. 2015:8:134.

15. Smith LB, Kasai S, Scott JG. Pyrethroid resistance in Aedes aegypti and Aedes albopictus: Important mosquito vectors of human diseases. Pestic Biochem Physiol. 2016;133:1-12

16. Su X, Guo Y, Deng J, Xu J, Zhou G, Zhou T, et al. Fast emerging insecticide resistance in Aedes albopictus in Guangzhou, China: Alarm to the dengue epidemic. PLoS Negl Trop Dis. 2019;13:e0007665.

17. Ishak IH, Riveron JM, Ibrahim SS, Stott R, Longbottom J, Irving $H$, et al. The Cytochrome P450 gene CYP6P12 confers pyrethroid resistance in kdr-free Malaysian populations of the dengue vector Aedes albopictus. Sci Rep. 2016:6:24707.

18. Janich AJ, Saavedra-Rodriguez K, Vera-Maloof FZ, Kading RC, Rodríguez $A D$, Penilla-Navarro $P$, et al. Permethrin resistance status and associated mechanisms in Aedes albopictus (Diptera: Culicidae) from chiapas. Mexico J Med Entomol. 2021:58:739-48.

19. Kasai SNL, Lam-Phua SG, Tang CS, Itokawa K, Komagata O, Kobayashi $M$, Tomita $T$. First detection of a putative knockdown resistance gene in major mosquito vector Aedes albopictus. Jpn J Infect Dis. 2011;64:217-21.

20. Chatterjee M, Ballav S, Maji AK, Basu N, Sarkar BC, Saha P. Polymorphisms in voltage-gated sodium channel gene and susceptibility of Aedes albopictus to insecticides in three districts of northern West Bengal India. PLoS Negl Trop Dis. 2018;12:e0006192.

21. Rinkevich FD, Du Y, Dong K. Diversity and convergence of sodium channel mutations involved in resistance to pyrethroids. Pestic Biochem Physiol. 2013;106:93-100.

22. Dong K, Du Y, Rinkevich F, Nomura Y, Xu P, Wang L, et al. Molecular biology of insect sodium channels and pyrethroid resistance. Insect Biochem Mol Biol. 2014;50:1-17.

23. Xu J, Bonizzoni M, Zhong D, Zhou G, Cai S, Li Y, et al. Multi-country survey revealed prevalent and novel F1534S mutation in voltage-gated sodium channel (VGSC) gene in Aedes albopictus. PLoS Negl Trop Dis. 2016;10:e0004696.

24. Gao JP, Chen HM, Shi H, Peng H, Ma YJ. Correlation between adult pyrethroid resistance and knockdown resistance $(\mathrm{kdr})$ mutations in 
Aedes albopictus (Diptera: Culicidae) field populations in China. Infect Dis Poverty. 2018;7:86.

25. Li Y, Xu J, Zhong D, Zhang H, Yang W, Zhou G, et al. Evidence for multipleinsecticide resistance in urban Aedes albopictus populations in southern China. Parasit Vectors. 2018;11:4.

26. Aguirre-Obando OA, Martins AJ, Navarro-Silva MA. First report of the Phe1534Cys kdr mutation in natural populations of Aedes albopictus from Brazil. Parasit Vectors. 2017;10:160.

27. Wei Y, Wang J, Wei Y-H, Song Z, Hu K, Chen Y, et al. Vector competence for DENV-2 among Aedes albopictus (Diptera: Culicidae) populations in China. Front Cell Infect Microbiol. 2021;11:649975.

28. Lu B. Fauna Sinica Insecta (Vol.8). Diptera Culicidae 1. Beijing: Science Press; 1997.

29. WHO. Guidelines for laboratory and field testing of mosquito larvicides. Geneva: World Health Organization; 2005.

30. WHO. Monitoring and managing insecticide resistance in Aedes mosquito populations: Interim guidance for entomologists; 2016.

31. Hall TA. BioEdit: a user-friendly biological sequence alignment editor and analysis program for Windows 95/98/NT. Nucleic Acids Symp Ser. 1999:41:95-8.

32. WHO. 22nd Report by the Expert Committee on Insecticides, WHO Tech. Rpt; 1976.

33. Wang Y, Jiang Z. Development and application of public health pesticides in China, 2013-2016. Chin J Vector Biol Control. 2016;27:421-5.

34. Meng F, Wang Y, Feng L, Liu Q. Review on dengue prevention and control and integrated mosquito management in China. Chin J Vector Biol Control. 2015;26:4-10.

35. Neng W, Yan X, Fuming H, Dazong C. Susceptibility of Aedes albopictus from China to insecticides, and mechanism of DDT resistance. J Am Mosa Control Assoc. 1992;8:394-7.

36. Li C, Yan Z, Jian G, Wu H, Hu Z. Resistance of Aedes albopictus to commonly used insecticides in urban area of Guangzhou. Chin J Hygienic Insecticides Equipments. 2013;19:487-9.

37. Yiguan W, Xin L, Chengling L, Su T, Jianchao J, Yuhong G, et al. A Survey of insecticide resistance in Aedes albopictus (Diptera: Culicidae) during a 2014 dengue fever outbreak in Guangzhou. China J Econ Entomol. 2017;110:239-44.

38. Li Y, Zhou G, Zhong D, Wang X, Hemming-Schroeder E, David RE, et al. Widespread multiple insecticide resistance in the major dengue vector Aedes albopictus in Hainan Province China. Pest Manag Sci. 2021;77:1945-53.

39. Hou J, Liu Q Wang J, Wu Y, LiT, Gong Z. Insecticide resistance of Aedes albopictus in Zhejiang Province. China Biosci Trends. 2020;14:248-54.

40. Liu H, Liu L, Cheng P, Yang L, Chen J, Lu Y, et al. Bionomics and insecticide resistance of Aedes albopictus in Shandong, a high latitude and high-risk dengue transmission area in China. Parasit Vectors. 2020;13:11.

41. Zhao C, Zhu C, Jia Q, Yan D, Liu G, Wu H, et al. Resistance of Aedes albopictus to commonly used insecticides in different areas of China, 2017-2018. Chin J Vector Biol Control. 2020;31:126-32.

42. Dusfour I, Vontas J, David JP, Weetman D, Fonseca DM, Corbel V, et al. Management of insecticide resistance in the major Aedes vectors of arboviruses: advances and challenges. PLoS Negl Trop Dis. 2019;13:e0007615.

43. Achee NL, Grieco JP, Vatandoost H, Seixas G, Pinto J, Ching-Ng L, et al. Alternative strategies for mosquito-borne arbovirus control. PLoS Negl Trop Dis. 2019;13:e0006822

44. Chen H, Li K, Wang X, Yang X, Lin Y, Cai F, et al. First identification of kdr allele F1534S in VGSC gene and its association with resistance to pyrethroid insecticides in Aedes albopictus populations from Haikou City, Hainan Island China. Infect Dis Poverty. 2016;5:31.

45. Wei Y, Wang J, Song Z, He Y, Zheng Z, Fan P, et al. Patterns of spatial genetic structures in Aedes albopictus (Diptera: Culicidae) populations in China. Parasit Vectors. 2019;12:552

46. Shapiro LLM, Whitehead SA, Thomas MB. Quantifying the effects of temperature on mosquito and parasite traits that determine the transmission potential of human malaria. PLoS Biol. 2017;15:e2003489.

47. Tantely ML, Tortosa P, Alout H, Berticat C, Berthomieu A, Rutee A, et al. Insecticide resistance in Culex pipiens quinquefasciatus and Aedes albopictus mosquitoes from La Réunion Island. Insect Biochem Mol Biol. 2010;40:317-24.
48. Ngoagouni C, Kamgang B, Brengues C, Yahouedo G, Paupy C, Nakouné E, et al. Susceptibility profile and metabolic mechanisms involved in Aedes aegypti and Aedes albopictus resistant to DDT and deltamethrin in the Central African Republic. Parasit Vectors. 2016;9:599.

\section{Publisher's Note}

Springer Nature remains neutral with regard to jurisdictional claims in published maps and institutional affiliations.
Ready to submit your research? Choose BMC and benefit from:

- fast, convenient online submission

- thorough peer review by experienced researchers in your field

- rapid publication on acceptance

- support for research data, including large and complex data types

- gold Open Access which fosters wider collaboration and increased citations

- maximum visibility for your research: over $100 \mathrm{M}$ website views per year

At BMC, research is always in progress.

Learn more biomedcentral.com/submissions 